\title{
The Role of Ginkgo biloba Extract as Monotherapy in Improving the Outcomes of Patients with Metabolic Syndrome: A Pilot Comparative Study with Metformin
}

\author{
Tavga A. Aziz ${ }^{*} 1$
}

*Department of Pharmacology and Toxicology, College of Pharmacy, University of Sulaimani, Kurdistan, Iraq

\section{Abstract}

The present study evaluates the effects of Ginkgo biloba extract as monotherapy on the glycemic status, insulin resistance (IR), body mass index (BMI), and visceral adiposity index (VAI), in addition to the inflammatory markers, oxidative status and leptin level in patients with metabolic syndrome in comparison with metformin.

The study is a randomized, double-blind pilot study conducted during the period May to September, 2020. Fifty patients were recruited in the study and they were allocated into two groups (25 per each group): Ginkgo biloba and Metformin groups, they received (120 mg Ginkgo biloba extract/ capsule) and (500 mg Metformin/ capsule) respectively; orally as a single dose for 90 days. Blood samples were taken at zero time and after 90 days and utilized for analysis of blood glucose, HbA1c, insulin and leptin levels, lipid profile, TAOS, hsCRP, TNF $\alpha$ and IL-6. Additionally, hematological markers, liver and kidney function tests also measured. Body mass index, waist circumference (WC), IR, and VAI were determined at baseline and after 90 days of GKB extract and metformin treatment.

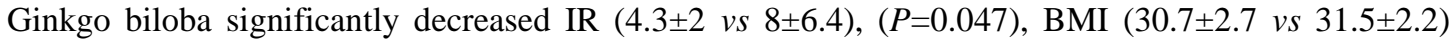
$(P<0.048)$, VAI $(183.7 \pm 101$ vs $245.7 \pm 104.5),(P=0.036)$ and leptin level $(4976 \pm 1803$ vs $7317 \pm 2807),(P=0.037)$ compared with baseline value. However, no significant decrease was observed on HbA1c and insulin level. GKB also significantly decreased IL-6 level $(19.8 \pm 19$ vs 28 \pm 22$),(P=0.018)$ and TNF $\alpha$ level $(130.6 \pm 33.7 v s$ 182.8 \pm 36.6$),(P<0.001)$ with significant increase in HDL level $(41.3 \pm 11.6$ vs $30.7 \pm 4.8),(P=0.01)$ and TAOC $(52.8 \pm 27$ vs $37 \pm 19.5),(P=0.01)$ compared to the baseline values. Metformin led to a significant decrease $(12.9 \pm 6$ vs $27 \pm 19 \mu \mathrm{IU} / \mathrm{ml})$ in insulin level $(\mathrm{P}=0.032)$ and $\mathrm{IR}(6.7 \pm 5$ vs $12.8 \pm 9),(\mathrm{P}=0.039)$, with significant increase in HDL level $(49.21 \pm 4.4$ vs $38.08 \pm 3.8)$, $(\mathrm{P}=0.001)$ compared with the pre-treatment value.

The use of $120 \mathrm{mg} \mathrm{GKB}$ as monotherapy was effective in improving the outcomes of metabolic syndrome suggesting it as a good candidate to be used in the clinical setting with a larger sample size and for a longer period of time.

Keywords: Ginkgo biloba, Metabolic syndrome, Glycemic status, Visceral adiposity index, Inflammatory markers.

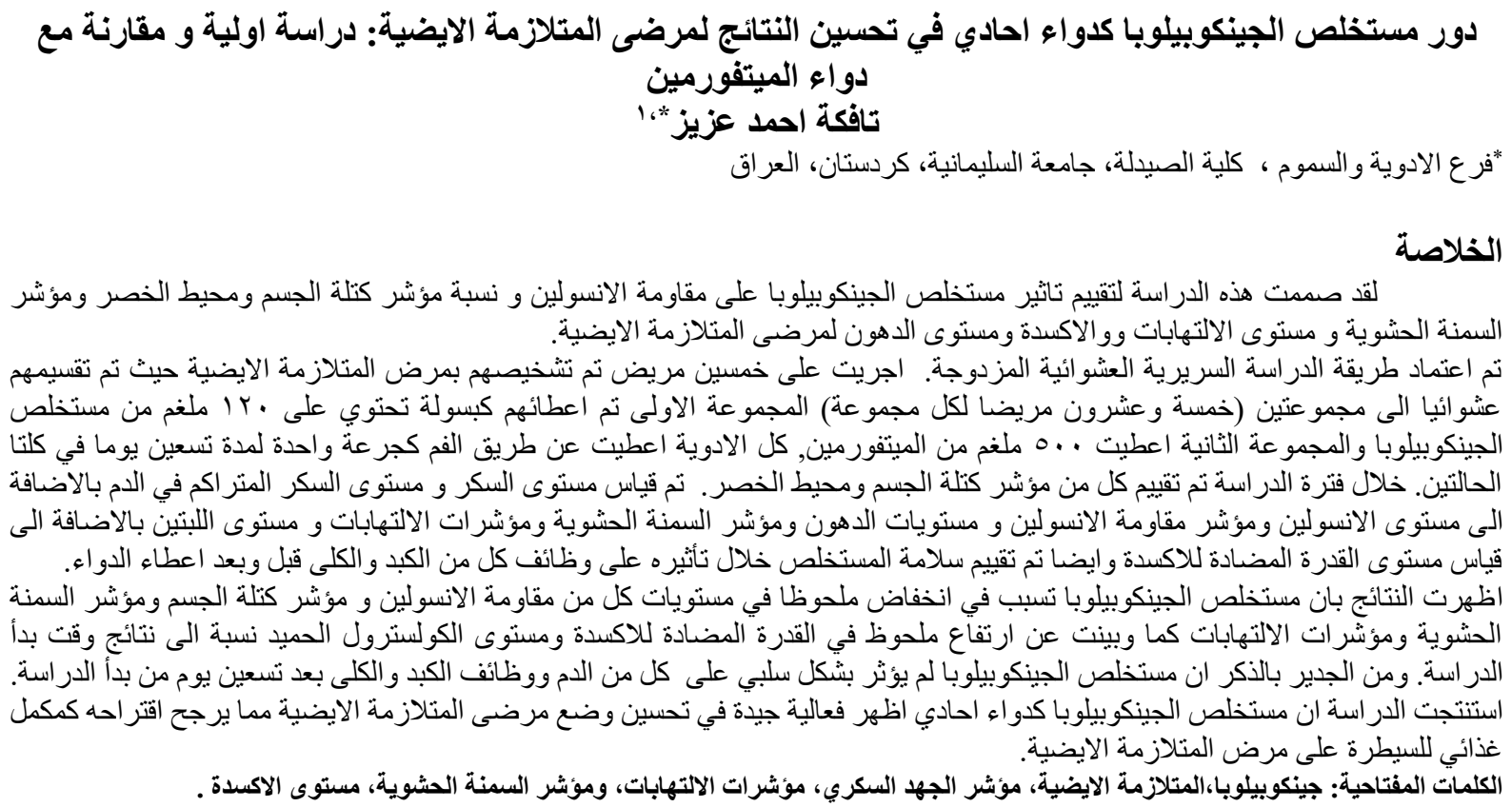

${ }^{1}$ Corresponding author E-mail: tavga.aziz@ univsul.edu.iq

Received: 21/11/2020

Accepted: 21/1/2021

Iraqi Journal of Pharmaceutical Science 


\section{Introduction}

Metabolic syndrome (MetS) is a debatable clinical body characterized by metabolic disturbances. The etiology of the disease contributes to several factors upon which genetic and environmental factors have a critical role in the disposition of the disease ${ }^{(1)}$. There are some risk factors such as obesity, insulin resistance, dyslipidemia, and hypertension that contribute to the pathogenesis of the disease. Improper management of MetS may end up with cardiovascular events and type 2 diabetes ${ }^{(2,3)}$. Obesity is considered pandemic and the prevalence has increased pronouncedly ${ }^{(4)}$. Large bodies of evidence proved the relation between body weight, hyperlipidemia, ${ }^{(5)}$ metabolic syndrome $^{(6)}$ and type 2 diabetes $^{(4) .}$ In addition to the pivotal role of obesity in the development of insulin resistance $(4,7)$. Weight reduction is the first nonpharmacological strategy in the management of MetS, however people are not willing to adhere with a restricted low calories diet for a long period of time $(1,8,9)$. additionally, Some inflammatory markers are known to increase in patients with MetS (10). However, the relationship between inflammation and metabolic syndrome are not clear. One of the theories that explain this link could be the fact that obese peoples with MetS have high level of adipose tissue that contribute in the release of proinflammatory cytokines directly into the circulatory system ${ }^{(11)}$. The increase in the levels of the inflammatory markers do not resemble that of acute or chronic inflammation since it is not associated with infection or serious tissue damage, it is a low grade of inflammation mainly known as meta-inflammation $^{(12)}$.

The multifactorial etiologies of MetS render the management of the disease to be difficult because we need more than one medication to control the symptoms of the disease like hyperglycemia, hypertension, and dyslipidemia with truncal obesity $(1,13)$. Polypharmacy is usually associated with increasing incidence of non-adherence, adverse reactions and drug interactions ${ }^{(14,15)}$. Therefore, the search for new medication that possesses more than one mechanism to control the disease is of value.

Medicinal plants have a long history in the management of various metabolic illnesses (16), Ginkgo biloba L. leaf extract (GKB extract), is among the nutraceuticals that gained great attention by the researchers because of its numerous biologically active constituents that may modify insulin action and/or production $(17,18)$. the plant is known for its antioxidant (19), anti-inflammatory ${ }^{(20)}$ and hypolipedemic activity (21, 22). Furthermore, ginkgo biloba proved to be effective in improving glycemic status and insulin sensitivity (23, 24). Recently GKB was shown to be effective as add-on therapy with metformin in patients with T2DM and MetS ${ }^{(25)}$, suggesting it as a good candidate to be tested as monotherapy in these diseases. Accordingly, the present study was designed to evaluate the effect of GKB alone on the outcome of metabolic syndrome.

\section{Patients, Materials and Methods Patients}

The study protocol was approved by the Ethical Committee of the College of Medicine/University of Sulaimani (certificate no 507/1024), and has been approved in Iranian Registry of Clinical Trials with registration reference IRCT20200803048285N1. The study was carried out in accordance with the principles of the Declaration of Helsinki as revised in 2000 (A set of ethical principles regarding human experimentation developed for the medical community by the World Medical Association (26). Written informed consent was obtained from each participant prior to enrollment in this pilot study.

\section{Materials}

Ginkgo biloba extract, as a standardized powder (EGb761), was obtained from Apollo Healthcare Resources, Singapore; metformin (Met) tablets (500 mg, Merck Sante S.A.S., France) were obtained from the verified and licensed pharmacy.

\section{Methods \\ Study design and patient treatment}

The study was a randomized, doubleblinded pilot study conducted between May to September 2020 at the Center of Diabetes and Endocrine Glands, Directory of Health/ Sulaimani city. The patients were recruited from public hospitals and private clinics according to the selection criteria. According to the inclusion criteria, patients of both sexes with the age range of 25-65 years, diagnosed by a specialist physician as having metabolic syndrome depending on the guideline of metabolic syndrome (27). The exclusion criteria included pregnancy, ischemic heart disease, cardiac arrhythmias, glucose-6-phosphate dehydrogenase (G6PD) deficiency, bleeding disorders, seizures, and known hypersensitivity to any component of the trial drugs (GKB extract and Metformin). Moreover, patients on supplements that contain multivitamins and polyphenols were also excluded.

Sixty patients were originally screened for eligibility; only 50 were eligible and randomized into two groups (25 patients each) as follows: Metformin (500 mg tablet) group and GKB group received GKB extract (120 mg/capsule) as a single dose for 90 days. The GKB capsules were prepared in the laboratory of pharmaceutics, College of Pharmacy, University of Sulaimani. Patient followup was performed on monthly base to ensure patient compliance. 
Unfortunately, only 39 patients; 19 patients from the first group and 20 patients from the second group were completed the study and included in the final data analysis (Figure 1).
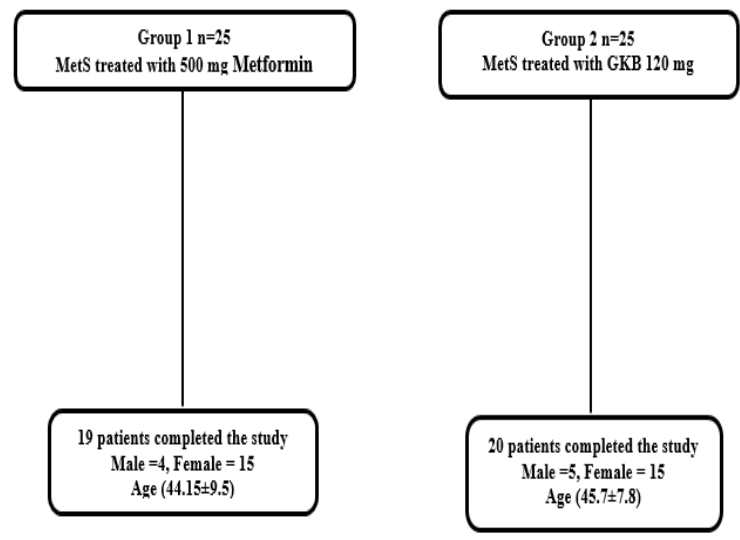

Figure 1. Flowchart shows the screening, recruitment and randomization of patients.

\section{Anthropometric outcomes}

Anthropometric measures were evaluated at baseline and after 90 days at the end of the treatment. Height and weight were measured by an electronic scale and a wall-mounted stadiometer. Waist circumference was measured by a tape measure. Each measurement was taken twice, and the average values were recorded. In addition, the body mass index (BMI) was calculated according to the following formula:

$$
\begin{aligned}
\text { BMI = } & \text { weight }(\mathrm{kg}) / \text { height } 2(\mathrm{~m} 2)^{(28)}{ }^{(2)} \\
& \text { Visceral adiposity index }(\mathrm{VAI}) \text { was also }
\end{aligned}
$$
measured. The VAI is an empirical mathematical model, which is gender specific and based on simple anthropometric (BMI and WC) and functional parameters (TG and HDL-c), which is an indicator of body fat distribution and function. Calculation of VAI was according to the formula given by Amato et $\mathrm{al}^{(29)}$. The formula is a linear equation derived by extrapolation from the relationship between BMI and $\mathrm{WC}$ in a healthy normal/overweight population. Distribution mode of adipose tissue was corrected for TG and HDL-c levels to determine the VAI as follows:

Female VAI $=(\mathrm{WC} / 36.58+(1.89 \times \mathrm{BMI})) \times$ $(\mathrm{TG} / 0.81) \times(1.52 / \mathrm{HDL})$

Male VAI $=(\mathrm{WC} / 39.68+(1.88 \times \mathrm{BMI})) \times$ $(\mathrm{TG} / 1.03) \times(1.31 / \mathrm{HDL})$

Where WC is expressed in $\mathrm{cm}, \mathrm{BMI}$ in $\mathrm{kg} / \mathrm{m} 2$, TG in $\mathrm{mmol} / \mathrm{L}$, and HDL in $\mathrm{mmol} / \mathrm{L}$.

\section{Biochemical and hematological tests}

Patients were informed to be fasted for exactly $12 \mathrm{~h}$, then about $10 \mathrm{~mL}$ blood was taken from each patient at zero time (before starting treatment) and after 90 days' treatment by vein puncture. From which, about $2.0 \mathrm{~mL}$ was drawn in EDTA containing tubes and utilized for analysis of hematological markers fasting blood glucose (FBG)
${ }^{30}$, and HbA1c ${ }^{31}$ using colorimetric methods (Roche-cobas C 311, Roche Diagnostics GmbH, Mannheim, Germany). Insulin resistance calculated using HOMA-IR ${ }^{(32)}$. The remained $8.0 \mathrm{~mL}$ was drawn in plain tubes and left to clot, then centrifuged at $3000 \mathrm{rpm}$ for $20 \mathrm{~min}$ to obtain serum. The serum was stored at $-20^{\circ} \mathrm{C}$ unless analyzed immediately. The serum insulin content was measured using an immunoassay method ${ }^{33}$ (Roche-Cobas e 411; Hoffman-La Roche Ltd.). The serum was used for analysis of leptin ${ }^{34}$, total lipid profile ${ }^{35}$ using colorimetric methods (Roche-cobas C 311, Roche Diagnostics $\mathrm{GmbH}$, Mannheim, Germany). TNF $\alpha$ and IL6 were measured using human TNF $\alpha$ and human IL6 ELISA Kit respectively by a colorimetric method 36, 37 (Chromate, Awareness Technology, Inc., Palm City, FL, USA) and hsCRP measured using the ELISA Kit ${ }^{38}$. The serum was also used for the analysis of total antioxidant capacity using total antioxidant capacity (T-AOC) Assay Kit by a colorimetric method ${ }^{39}$ (Visible Spectrophotometer 721 , China). Liver ${ }^{(40)}$ and kidney functions test ${ }^{(41,}$ 42) and hematological markers ${ }^{(43)}$ were determined calorimetrically using ready-made kits (Randox, London, UK) according to the manufacturer's instructions.

\section{Statistical analysis}

The statistical analysis was performed using the GraphPad Prism 5.1 software (GraphPad Software, Inc., La Jolla, CA, USA). Descriptive statistics was utilized to compare the patient's characteristics between the two groups. Paired t-test was utilized to evaluate the difference between the pretreatment mean and post treatment mean of the same group. Unpaired t-test was utilized to evaluate the differences between post treatment mean of the different groups. Two-way analysis of variance, supported by Bonferroni's post hoc analysis, and analysis of covariance were used to determine the difference between the mean of independent samples at $\mathrm{P}$-value $<0.05$.

\section{Results}

The baseline data of the MetS patients were shown in Table 1. There were no statistically significant differences $(P>0.05)$ in all parameters between the Metformin and GKB groups including the age, gender, weight, WC, BMI and HbA1c. After 90 days of treatment, FBG levels of both GKB treated group and metformin treated group were non-significantly decreased $(125 \pm 17 \mathrm{mg} / \mathrm{dl}$ vs 126 $\pm 30)$ and $(135 \pm 11 \mathrm{mg} / \mathrm{dl}$ vs $141 \pm 17)$ respectively, $(P>0.05)$ compared with baseline values (Figure 2 A). Regarding the effects on insulin, 90 days' treatment with GKB extract non-significantly decreased $(20.6 \pm 17 \mu \mathrm{IU} / \mathrm{ml}$ vs $36.7 \pm 28)$ level $(P=$ $0.07)$ compared with baseline values, while treatment with metformin led to a significant decrease $(12.9 \pm 6 \mu \mathrm{IU} / \mathrm{ml}$ vs $27 \pm 19)$ in insulin levels compared with baseline values $(P=0.032)$ (Figure 2 B). Concerning the level of $\mathrm{HbA} 1 \mathrm{c}, \mathrm{GKB}$ treated 
group produced a non-significant decrease $(7 \% \pm 0.8 \%$ vs $7.2 \% \pm 1 \%)$ compared to the baseline value $(P=0.6)$ with no significant change produced by metformin (Figure $2 \mathrm{C}$ ). Regarding Insulin resistance, there was a significant decrease after 90

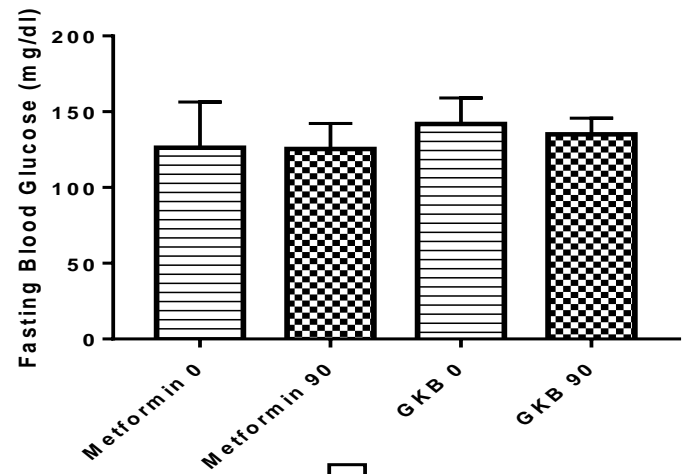

$\triangle$

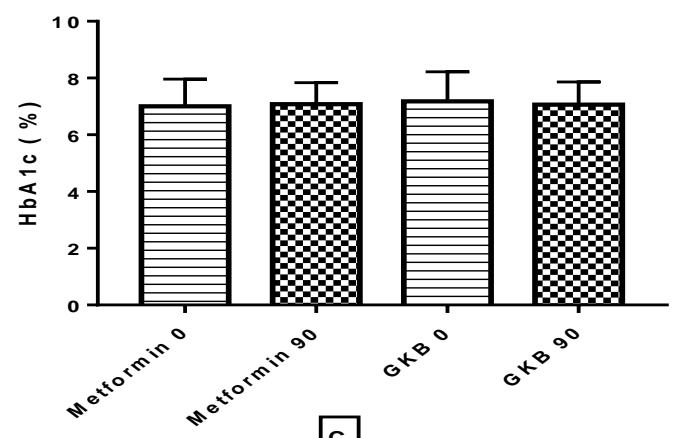

c days of treatment with each of GKB extract and metformin compared with the pre-treatment value (4.3 \pm 2 vs $8 \pm 6.4), \quad(6.7 \pm 5$ vs $12.8 \pm 9), \quad(P=0.047)$ and $(P=0.039)$ respectively (Figure $2 \mathrm{D})$.
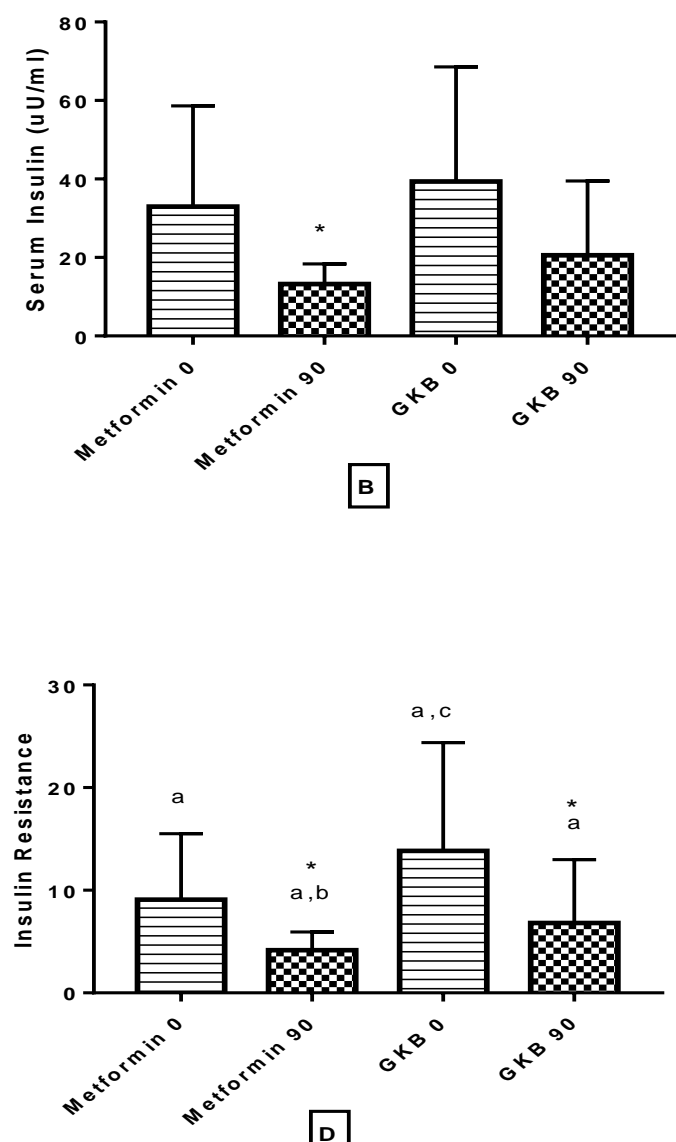

D

Figure 2: Effect of Gingko biloba extract (GKB) on the serum level of (A) Fasting Glucose (B) Insulin (C) HbA1c (D) Insulin Resistance of patients with metabolic syndrome. Values were presented as mean \pm S.D; * significantly different compared with baseline values (paired $t$-test, $P<0.05)$. Values with non-identical letters $(\mathrm{a}, \mathrm{b}, \mathrm{c})$ were significantly different among each other (ANOVA, $P<0.05$ ).

Table 1. Baseline characteristics of the randomly allocated metabolic syndrome patients

\begin{tabular}{||l|l|l|l||}
\hline \hline Parameters & $\begin{array}{l}\text { Metformin } \\
n=19\end{array}$ & $\begin{array}{l}\text { GKB } \\
n=20\end{array}$ & $P$ value \\
\hline Age $(\mathrm{yr})$ & $44.15 \pm 9.5$ & $45.7 \pm 7.8$ & 0.25 \\
\hline Male $(\%)$ & $4(21 \%)$ & $5(25 \%)$ & 0.42 \\
\hline Weight $(\mathrm{kg})$ & $79.46 \pm 13.46$ & $80.7 \pm 17$ & 0.18 \\
\hline BMI $\left(\mathrm{kg} / \mathrm{m}^{2}\right)$ & $32 \pm 7$ & $31.5 \pm 2.2$ & 0.56 \\
\hline WC $(\mathrm{cm})$ & $97.6 \pm 10.2$ & $102.2 \pm 5.5$ & 0.23 \\
\hline HbA1c $(\%)$ & $7 \pm 0.95$ & $7.2 \pm 1$ & 0.68 \\
\hline
\end{tabular}

P-value consider significant if $\mathrm{P}<0.05$. 
Figure 3 A clearly shows that the use of $120 \mathrm{mg}$ GKB extract, as a single oral dose for 90 days, significantly decreased BMI $(30.7 \pm 2.7$ vs $31.5 \pm 2.2)$ $(P<0.048)$ compared with baseline values, while administration of metformin resulted in a nonsignificant decrease $(32.4 \pm 6.9$ vs $32.8 \pm 7)$ in BMI compared with baseline values. Moreover, GKBtreated patients showed a non-significant decrease in waist circumference values $(99.6 \pm 5.5$ vs $102.2 \pm 5.5)$ $(P=0.06)$ compared with baseline values, while metformin did not significantly affect this parameter after 90 days (Figure 3 B). Regarding the effect on visceral adiposity index (VAI), (Figure $3 \mathrm{C}$ ) shows that in GKB treated group, there was a significant decrease $(183.7 \pm 101 v s 245.7 \pm 104.5)$ in VAI after 90 days of treatment compared with the baseline value $(P=0.036)$; meanwhile, a non-significant decrease $(158 \pm 77.8$ vs $195.6 \pm 145.5)$ in VAI was observed after 90 days of treatment with metformin $(P=0.26)$ compared with the pre-treatment value. GKB also resulted in a significant decrease $(4976 \pm 1803$ vs $7317 \pm 2807)$ in the level of leptin after 90 days' treatment $(P=0.037)$; compared with the pretreatment value with no significant change $(6169 \pm 2414$ vs $7176 \pm 2812)$ observed with the use of metformin $(P=0.22)$ (Figure $3 \mathrm{D})$.
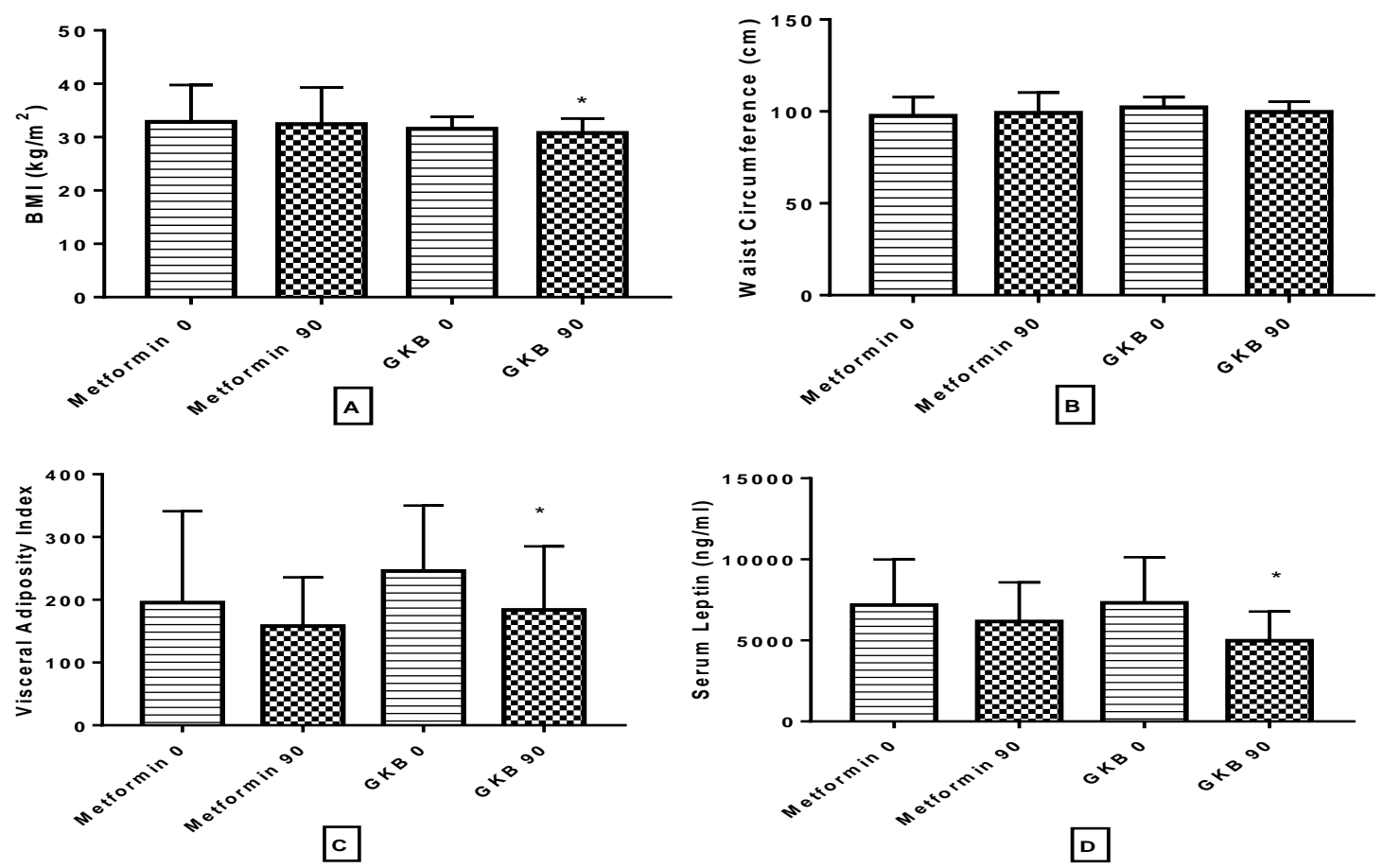

Figure 3. Effect of Gingko biloba extract (GKB) on the serum level of (A) BMI (B) Waist circumference (C) VAI and (D) Leptin of patients with metabolic syndrome. Values were presented as mean \pm S.D; * significantly different compared with baseline values (paired $t$-test, $P<0.05$ ).

After 90 days of treatment total cholesterol, triglyceride and serum LDL were non-significantly changed with each of GKB extract and metformin compared with the pre-treatment value (Figure $4 \mathrm{~A}$, $\mathrm{B}$ and $\mathrm{C})$. While serum HDL levels was significantly increased after 90 days of treatment with each of GKB extract $(41.3 \pm 11.6$ vs $30.7 \pm 4.8),(P=0.01)$ and metformin $(49.21 \pm 4.4$ vs $38.08 \pm 3.8),(P=0.001)$ compared with the pre-treatment value (Figure 4D).
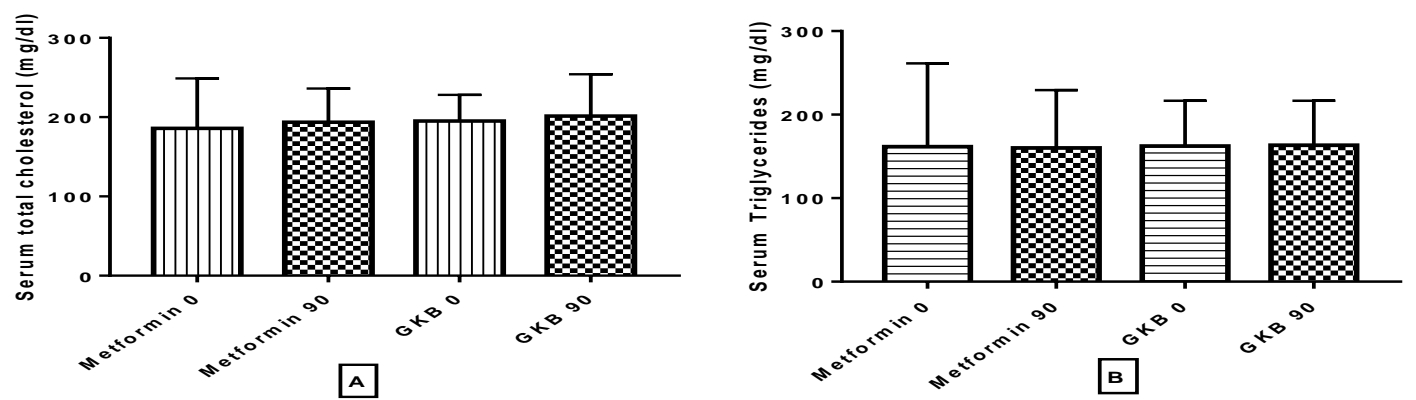

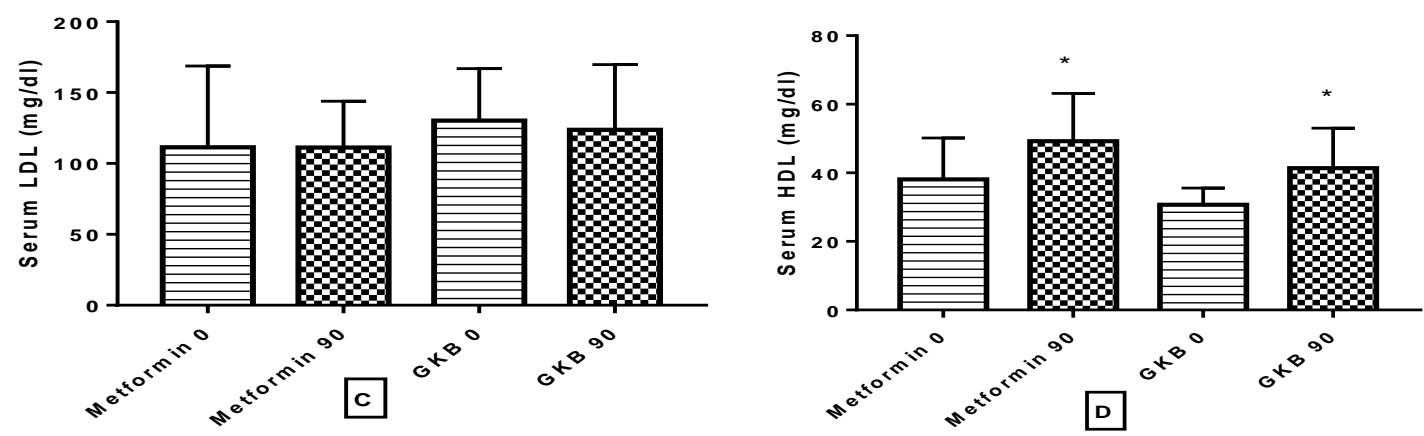

Figure 4. Effect of Gingko biloba extract (GKB) on the serum level of (A) Total cholesterol (B) Triglycerides (C) LDL and (D) HDL of patients with metabolic syndrome. Values were presented as mean \pm S.D; * significantly different compared with baseline values (paired $t$-test, $P<0.05$ ).

Regarding TNF $\alpha$ there was a significant decrease after 90 days of treatment with GKB extract

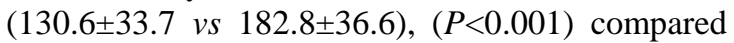
with the pre-treatment value and $(130.6 \pm 33.7 \mathrm{vs}$ $181.3 \pm 74), \quad(P<0.05)$ compared with metformin treated group (Figure $5 \mathrm{~A}$ ). While the use of $500 \mathrm{mg}$ metformin produced no significant change compared with the baseline value. Ninety days' treatment with GKB extract also produced a significant decrease in the level of IL6 $(19.8 \pm 19 v s$
$28 \pm 22),(P=0.018)$ compared with the pre-treatment value with non-significant decrease produced by group treated with metformin (Figure 5 B). Moreover, hs-CRP was non-significantly decreased in GKB treated group and non-significant increase produced by metformin treated group (Figure $5 \mathrm{C}$ ). Serum TAOC was significantly increased after 90 days of treatment with GKB extract $(52.8 \pm 27 v s$ $37 \pm 19.5), \quad(P=0.01)$; compared with the pretreatment value.
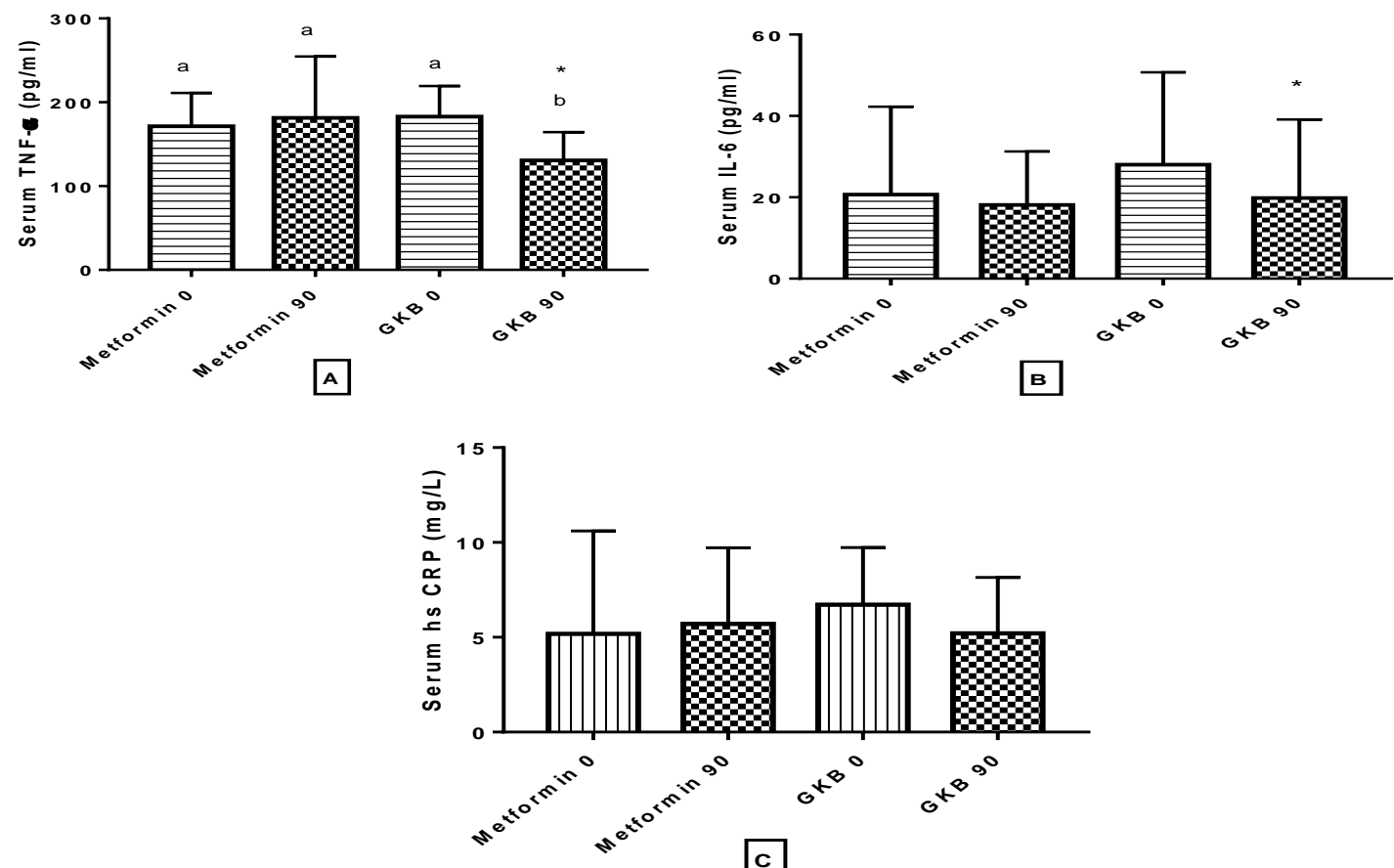

Figure 5. Effect of Gingko biloba extract (GKB) on the serum level of (A) TNF-a (B) IL6 (C) hs-CRP of patients with metabolic syndrome. Values were presented as mean \pm S.D; * significantly different compared with baseline values (paired $t$-test, $P<0.05)$. Values with non-identical letters $(a, b)$ were significantly different among each other (ANOVA, $P<0.05$ ). 
Metformin also increased the level of TAOC however it was statistically not significant (Figure 6). All the biochemical analyses regarding the liver functions indicated no alteration of values after 90 days of GKB treatment (Table 2), except serum ALP where significant decreases were reported in each of GKB and metformin treated groups compared with baseline values $(\mathrm{P}=0.02)$ and $(\mathrm{P}<0.001)$ respectively. For the kidney function tests; serum creatinine levels were significantly elevated compared with baseline values in the metformin-treated group $(\mathrm{P}=0.014)$ but still within the normal range, with no significant change in blood urea level in both treated groups (Table 3 ). Regarding the hematological markers; (Table 4) reveals significant increase $(\mathrm{P}=0.038)$ in $\mathrm{Hb}$ concentration in the GKB-treated patients after 90 days compared with baseline values. Meanwhile, platelet count significantly decreased in GKB treated group $(\mathrm{P}=0.014)$ and metformin treated group $(\mathrm{P}=0.011)$.

Table 2. Effect of Gingko biloba extract (GKB) on the liver function markers of patients with metabolic syndrome.

\begin{tabular}{||c|c|c|c|c||}
\hline \multirow{2}{*}{ Parameters } & \multicolumn{2}{|c|}{ Metformin $(n=19)$} & \multicolumn{2}{c||}{ GKB $(n=20)$} \\
\cline { 2 - 5 } & Baseline & after 90 days & baseline & after 90 days \\
\hline Serum AST (U/L) & $20.21 \pm 7.25^{\mathrm{a}}$ & $19.12 \pm 4.82^{\mathrm{a}}$ & $21.23 \pm 7.1^{\mathrm{a}}$ & $21.39 \pm 5.4^{\mathrm{a}}$ \\
\hline Serum ALT (U/L) & $17.11 \pm 8.2^{\mathrm{a}}$ & $15.7 \pm 5.2^{\mathrm{a}}$ & $24.57 \pm 13.5^{\mathrm{a}}$ & $23.15 \pm 8.8^{\mathrm{a}}$ \\
\hline Serum ALP (U/L) & $75.4 \pm 25.5^{\mathrm{a}}$ & $64.46 \pm 20 * \mathrm{a}$ & $86.7 \pm 24.8^{\mathrm{a}}$ & $75.8 \pm 21.9^{\mathrm{a}}$ \\
\hline
\end{tabular}

Values were presented as mean \pm S.D; n: number of patients; * significantly different compared with baseline values (paired t-test, $\mathrm{P}<0.05)$; values with different superscripts $(\mathrm{a}, \mathrm{b})$ within each parameter were significantly different (ANOVA, $\mathrm{P}<0.05)$.

Table 3. Effect of Gingko biloba extract (GKB) on the renal function markers of patients with metabolic syndrome.

\begin{tabular}{||c|c|c|c|c||}
\hline \hline \multirow{2}{*}{ Parameters } & \multicolumn{2}{|c|}{ Metformin $(n=19)$} & \multicolumn{2}{c|}{ GKB $(n=20)$} \\
\cline { 2 - 5 } & baseline & after 90 days & baseline & after 90 days \\
\hline Serum Urea $(\mathrm{mg} / \mathrm{dL})$ & $25 \pm 6.5^{\mathrm{a}}$ & $25.6 \pm 8.4^{\mathrm{a}}$ & $27.44 \pm 7.7^{\mathrm{a}}$ & $29.56 \pm 7.7^{\mathrm{a}}$ \\
\hline Serum Creatinin $(\mathrm{mg} / \mathrm{dL})$ & $0.65 \pm 0.12^{\mathrm{a}}$ & $0.75 \pm 0.12^{* \mathrm{a}}$ & $0.64 \pm 0.17^{\mathrm{a}}$ & $0.7 \pm 0.17^{\mathrm{a}}$ \\
\hline
\end{tabular}

Values were presented as mean \pm S.D; n: number of patients; * significantly different compared with baseline values (paired t-test, $\mathrm{P}<0.05)$; values with different superscripts $(\mathrm{a}, \mathrm{b})$ within each parameter were significantly different (ANOVA, $\mathrm{P}<0.05$ ).

Table 4. Effect of Gingko biloba extract (GKB) on the hematological markers of patients with metabolic syndrome.

\begin{tabular}{||l|c|c|c|c||}
\hline \multirow{2}{*}{ Parameters } & \multicolumn{2}{|c|}{ Metformin $(n=19)$} & \multicolumn{2}{c||}{ GKB $(n=20)$} \\
\cline { 2 - 5 } & Baseline & after 90 days & baseline & after 90 days \\
\hline $\mathrm{Hb}(\mathrm{g} / \mathrm{dL})$ & $12.9 \pm 1.2$ & $13.4 \pm 1.5$ & $13.3 \pm 1.2$ & $13.9 \pm 1.3^{*}$ \\
\hline $\mathrm{Hct}(\%)$ & $37.9 \pm 3.8$ & $39.4 \pm 4.6$ & $38.9 \pm 4.6$ & $40.8 \pm 4.1$ \\
\hline $\mathrm{RBC}$ countx10 $(\mathrm{cell} / \mathrm{s} / \mu \mathrm{L})$ & $4.4 \pm 0.5$ & $4.6 \pm 0.5$ & $4.7 \pm 0.58$ & $4.9 \pm 0.4$ \\
\hline WBCcount $\times 10^{3}$ cells $/ \mu \mathrm{L}$ & $8.5 \pm 2.3$ & $8.1 \pm 1.6$ & $8.1 \pm 1.8$ & $7.6 \pm 1.7$ \\
\hline Platelets count $\times 10^{9}$ cells/L & $257 \pm 50$ & $223 \pm 57^{*}$ & $237 \pm 43$ & $201 \pm 40^{*}$ \\
\hline
\end{tabular}

Values were presented as mean \pm S.D; $n$ : number of patients; * significantly different compared with baseline values (paired $t$-test, $P<0.05$ ). 


\section{Discussion}

The first step in the treatment of metabolic syndrome is modification of life style via avoiding sedentary life style and this includes decreasing food intake and increasing physical activity, however unfortunately only a few patients are willing to modify their life style without the aid of medications. In the present study, GKB for the first time has been used as a monotherapy in patients with MetS; and it was effective in modifying and improving some of the components of MetS such as insulin resistance, BMI, VAI and HDL in addition to the inflammatory markers and the antioxidant status. Similarly, many studies have shown the effectiveness of GKB in improving insulin sensitivity $(23,44,45)$. The glycemic status have been improved by the use of GKB in the current study however, the change was statistically not significant which could be attributed to the small dose and/or the short period of treatment, additionally, the exact effect of the plant cannot judge on such a small sample size. Moreover, it was effectively enhanced insulin sensitivity and this finding was in tune with other studies $(44,24)$. Obesity secondary to high fat food produces alterations in the regulation of peripheral metabolism and food intake, subsequently decreasing insulin sensitivity, enhancing weight gain, and other metabolic disorders $(46,47)$. In many countries, obesity is considered as a major health problem and the primary goal is how to decrease the prevalence of obesity (48), and in spite of the efforts for minimizing obesity, still non-pharmacological interventions are inadequate to achieve satisfaction $(9,49,4)$, and because of the high risk associated with obesity in developing insulin resistance (5); additional medications are required to accomplish the necessity in the treatment of obesity. Nutraceutical recognized from traditional medicinal plants may represent a good choice for the development of new medications targeting obesity. In the current study, GKB extract successfully decreased BMI and WC; and this effect could be attributed to the terpenoid component of the plant that have the ability to inhibit the activity of pancreatic lipase (PL), which may in part give some clues about the reduction of body fat mass. Moreover, GKB was found to significantly inhibit PL ${ }^{(50)}$, which may attribute to the reduction of BMI in the current study. While metformin did not affect BMI and WC which could be due to the small dose used in the study and relatively short period of treatment ${ }^{(51)}$. GKB was effective in decreasing VAI and this finding was consistent with other study which demonstrated that prolonged treatment with GKB stimulated a noticeable visceral adiposity loss, improvement of insulin sensitivity via stimulation of insulin signaling cascade in gastrocnemius muscle ${ }^{(52)}$.
Another parameter that screened in this study is leptin; leptin is increasingly being involved in the etiology of metabolic disorders. It is one of the vital hormones expressed by the adipose tissue, and it has a critical role in regulating food consumption and energy production through its action on the hypothalamic nucleus. It has been reported that leptin shares the same signaling pathway with insulin. ${ }^{(53,54)}$ Mutation in leptin or its receptor results in improper leptin signaling and eventually increases food consumption and attenuates energy liberation in humans and experimental animals in spite of obesity ${ }^{(55)}$. In the present study, GKB significantly decreased the serum levels of leptin and the exact mechanism of such finding is unclear. However, the previously reported decrease in visceral adiposity (18), could be of value in explaining the changes in serum leptin. Additionally, GKB might exert a positive antiinflammatory effect on the hypothalamus, with a consequent reduction of the levels of orexigenic peptide and/or increasing anorexigenic peptide levels, which may promote weight loss via suppressing the appetite ${ }^{(24)}$. In the present study, GKB as monotherapy in patients with MetS was effective in modifying and improving some of the components of MetS such as HDL and metainflammation. Many studies have shown the effectiveness of GKB in improving glycemic status $(23,44,45)$, and ameliorating the inflammatory response ${ }^{(56,24)}$. Recently, the role of the oxidative stress and the pro-inflammatory mediators have been proved in the pathogenesis of insulin resistance; hence, attenuating the process of the inflammatory response is one of the therapeutic strategies to prevent the development and progression of insulin resistance ${ }^{(57)}$. The antiinflammatory effect of GKB demonstrated through attenuating the inflammatory markers; the study showed a pronounced decrease in the level of TNF$\alpha$ which demonstrates a significant change with the baseline value and with the group treated with metformin. GKB also produced a significant decrease in the serum level of IL6 compared to the baseline value. This anti-inflammatory effect could be attributed to the modulating effect on the expression of many inflammatory mediators and the ability of the plant to downregulate nitric oxide level and prostaglandin E2 formation along with decreasing proinflammatory cytokines and upregulating NF-kB factor ${ }^{(24,58,59)}$. 
The relationship between oxidative stress and inflammation is greatly documented ${ }^{(60,61)}$. Evidence from many studies proved the role of reactive species in the pathology of many chronic inflammatory diseases (62, 63). Among the inflammatory cytokines that modulate the inflammatory response is TNF- $\alpha$ which has a pivotal role in the generation of reactive species and enhance the expression of other inflammatory cytokines. Targeting TNF- $\alpha$ may participate in the downregulation of the inflammatory responses ${ }^{(64)}$. The current study revealed a potent antioxidant capacity exhibited by GKB; many mechanisms are proposed for this effect such as chelation of transition metals, scavenging of reactive oxygen species and enhancing the production of antioxidant molecules ${ }^{(65)}$. Furthermore, GKB has been reported to attenuate oxidative damage in previous studies ${ }^{(19}$ ' 65).

Moreover, the plant exerted no deleterious effect on the liver, kidney and the hematological markers. Taking all these findings together suggests GKB as a good candidate to be tested on a larger sample size of MetS patients and for a longer period of time to explore the exact beneficial effect of the plant in this respect.

\section{Limitations}

The major limitations of this study are the small sample size and the relatively short duration of treatment. Therefore, future studies are warranted to determine the long-term effect of GKB extract by following up a larger study population.

\section{Conclusion}

The use of $120 \mathrm{mg}$ GKB as monotherapy was effective in improving the outcomes of metabolic syndrome through decreasing insulin resistance, BMI, VAI, and leptin levels, and it was also effective in decreasing the inflammatory markers and increasing the antioxidant capacities in comparison with metformin suggesting it as a good candidate to be used in the clinical setting with a larger sample size and for a longer period of time.

\section{Acknowledgments}

The author appreciates the College of Pharmacy, University of Sulaimani, and the Center of Diabetic and Endocrine Glands for their support and for providing the facilities to complete this project.

\section{Disclosure}

The author reports no conflicts of interest in this work.

\section{References}

1. Srikanthan K, Feyh A, Visweshwar H, Shapiro JI, Sodhi K. Systematic review of metabolic syndrome biomarkers: A panel for early detection, management, and risk stratification in the West Virginian population. Int J Med Sci. 2016;13(1):25-38.

2. Alberti KGMM, Eckel RH, Grundy SM, Zimmet P Z, Cleeman J I, Donato K A, et al. Harmonizing the metabolic syndrome: A joint interim statement of the international diabetes federation task force on epidemiology and prevention; National heart, lung, and blood institute; American heart association; World heart federation; International atherosclerosis society; And international association for the study of obesity. Circulation. 2009;120(16):1640-1645.

3. Thaman R, Arora G. Metabolic syndrome: definition and pathophysiology- the discussion goes on! J Physiol Pharmacol Adv. 2013;3(3):48-56.

4. Pereira-Lancha LO, Campos-Ferraz PL, Lancha AH. Obesity: Considerations about etiology, metabolism, and the use of experimental models. Diabetes, Metab Syndr Obes Targets Ther. 2012;5 (4):75-87.

5. Klop B, Elte JWF, Cabezas MC. Dyslipidemia in obesity: Mechanisms and potential targets. Nutrients. 2013;5(4):1218-1240.

6. Ginsberg HN, Zhang Y-L, Hernandez-Ono A. metabolic syndrome: Focus on dyslipidemia. Obesity. 2006;14(2S):41S-49S.

7. Kahn BB, Flier JS. Obesity and insulin resistance. J Clin Invest. 2000;106(4):473-481.

8. Klein S, Sheard NF, Pi-Sunyer X, Daly A, Wylie-Rosett J, Kulkarni K, et al. Weight management through lifestyle modification for the prevention and management of type 2 diabetes: Rationale and strategies. A statement of the American Diabetes Association, the North American Association for the Study of Obesity, and the American Society for Clinical Nutrition. Am J Clin Nutr. 2004;80(2):257-263.

9. Lemstra M, Bird Y, Nwankwo C, Rogers M, Moraros J. Weight loss intervention adherence and factors promoting adherence: a metaanalysis. Patient Prefer Adherence. 2016;10 (8):1547-1559.

10. Festa A, D'Agostino R, Howard G, Mykkänen L, Tracy RP, Haffner SM. Chronic subclinical inflammation as part of the insulin resistance syndrome: The insulin resistance atherosclerosis study (IRAS). Circulation. 2000;102(1):42-47.

11. Di Lorenzo C, Dell'Agli M, Colombo E, Sangiovanni E, Restani P. Metabolic syndrome and inflammation: A critical review of in vitro and clinical approaches for benefit assessment 
of plant food supplements. Evidence-based Complement Altern Med. 2013;2013 (1): 1-10.

12. Hotamisligil GS. Inflammation and metabolic disorders. Nature. 2006;444(7121):860-867.

13. Bruce $\mathrm{KD}$, Byrne $\mathrm{CD}$. The metabolic syndrome: Common origins of a multifactorial disorder. Postgrad Med J. 2009;85(1009):614621.

14. Manju C., Razak R, Chandini R, Athira B. Pharmacist intervention in medication adherence in patients with type II diabetes mellitus. Int J Pharm Sci Res. 2016;7(1):358362.

15. Khandeparkar A, Rataboli P. A study of harmful drug-drug interactions due to polypharmacy in hospitalized patients in Goa Medical College. Perspect Clin Res. 2017;8(4):180-186.

16. Davì G, Santilli F, Patrono C. Nutraceuticals in diabetes and metabolic syndrome. Cardiovasc Ther. 2010;28(4):216-226.

17. Rhee KJ, Lee CG, Kim SW, Gim DH, Kim HC, Jung BD. Extract of Ginkgo biloba ameliorates streptozotocin- induced type 1 diabetes mellitus and high-fat diet- induced type 2 diabetes mellitus in mice. Int $\mathbf{J}$ Med Sci. 2015;12(12):987-994.

18. Aziz TA, Hussain SA, Mahwi TO, Ahmed ZA. Efficacy and safety of Ginkgo biloba extract as an "add-on" treatment to metformin for patients with metabolic syndrome: A pilot clinical study. Ther Clin Risk Manag. 2018;14 (7):1219-1226.

19. He YT, Xing SS, Gao L, Wang J, Xing QC, Zhang W. Ginkgo biloba attenuates oxidative DNA damage of human umbilical vein endothelial cells induced by intermittent high glucose. Pharmazie. 2014;69(3):203-207.

20. Kaur S, Sharma N, Nehru B. Anti-inflammatory effects of Ginkgo biloba extract against trimethyltin-induced hippocampal neuronal injury. 2018;26(1):87-104.

21. Kang H. Hypocholesterolemic Effect of Ginkgo biloba seeds extract from high fat diet mice. 2017;23(2):138-143.

22. Dubey AK, Devi A, Kutty G, Shankar RP. Hypolipidemic Activity of Ginkgo biloba Extract, EGb 761 in Hypercholesterolemic Wistar Rats. Iran J Pharmacol Ther. 2005;4(1):9-12.

23. Cheng D, Liang B, Li Y. Antihyperglycemic effect of ginkgo biloba extract in streptozotocin-induced diabetes in rats. Biomed Res Int. 2013;2013(1):1-7.

24. Hirata BKS, Banin RM, Dornellas APS, de Andrade IS, Zemdegs JC, Caperuto LC, et al. Ginkgo biloba extract improves insulin signaling and attenuates inflammation in retroperitoneal adipose tissue depot of obese rats. Mediators Inflamm. 2015;2015(1):1-9.

25. Aziz TA, Hussain SA, Mahwi TO, Ahmed ZA, Rahman HS, Rasedee A. The efficacy and safety of Ginkgo biloba extract as an adjuvant in type 2 diabetes mellitus patients ineffectively managed with metformin: A double-blind, randomized, placebo-controlled trial. Drug Des Devel Ther. 2018;12(4):735-742.

26. Association WM. World Medical Association declaration of Helsinki: Ethical principles for medical research involving human subjects. JAMA - J Am Med Assoc. 2013;310(20):21912194.

27. Hlcox J, Quyyumi A. Metabolic syndrome: Overview and current guidelines. Cardiol Rev Artic. 2005;11(part1):1-12.

28. 28. : Nihiser AJ, Lee SM, Wechsler $H$, McKenna M, Odom E, Reinold C TD, L G-S. Body mass index measurement in schools. J Sch Health. 2007; 77(10): 651-671.

29. Amato MC, Giordano C. Visceral adiposity index: An indicator of adipose tissue dysfunction. Int J Endocrinol. 2014;2014(1):17.

30. Barham D, Trinder P. An improved colour reagent for the determination of blood glucose by the oxidase system. Analyst. 1972;97(1151):142-145.

31. Abraham EC, Huff TA, Cope ND, Wilson JB, Bransome ED, Huisman TH. Determination of the glycosylated hemoglobins (Hb A1) with a new microcolumn procedure. Suitability of the technique for assessing the clinical management of diabetes mellitus. Diabetes. 1978;27(9):931-937.

32. Esteghamati A, Ashraf $\mathrm{H}$, Khalilzadeh $\mathrm{O}$, Zandieh A, Nakhjavani M, Rashidi A,et al. Optimal cut-off of homeostasis model assessment of insulin resistance (HOMA-IR) for the diagnosis of metabolic syndrome: Third national surveillance of risk factors of noncommunicable diseases in Iran (SuRFNCD2007). Nutr Metab. 2010;7(4):1-8.

33. Hlnsberg WD, Milby KH, Zare RN. Determination of insulin in serum by enzyme immunoassay with fluorimietric detection. Anal Chem. 1981;53(9):1509-1512.

34. Chow VTK, Phoon MC. Measurement of serum leptin concentrations in university undergraduates by competitive ELISA reveals correlations with body mass index and sex. Am J Physiol - Adv Physiol Educ. 2003;27(1-4):7077.

35. Covaci A, Voorspoels S, Thomsen C, van Bavel B, Neels H. Evaluation of total lipids using enzymatic methods for the normalization of persistent organic pollutant levels in serum. Sci Total Environ. 2006;366(1):361-366. 
36. Rendevski V, Aleksovski B, Stojanov D, Mihajlovska-Rendevska A, Aleksovski V, Baneva-Dolnenec N, et al. Validation of the ELISA method for quantitative detection of TNF- $\alpha$ in patients with intracerebral hemorrhage. Open Access Maced J Med Sci. 2017;5(6):703-707.

37. Helle M, Boeije L, de Groot E, de Vos A, Aarden L. Sensitive ELISA for interleukin-6. Detection of IL-6 in biological fluids: synovial fluids and sera. J Immunol Methods. 1991;138(1):47-56.

38. Luo Y, Zhang B, Chen M. Sensitive and rapid quantification of C-reactive protein using quantum dot-labeled microplate immunoassay. J Transl Med. 2012;10(1):24-33.

39. Rahnama A, Razavi SA, Hedayati M, Razmi N. Total antioxidant capacity determination with colorimetric method and microplate reading format and comparison with chemilumin Essence Assay. Eur Online J Nat Soc Sci. 2015;4(4):875-881.

40. Reitman $S$, frankel $S$. A colorimetric method for the determination of serum glutamic oxalacetic and glutamic pyruvic transaminases. Am J Clin Pathol. 1957;28(1):56-63.

41. Wilcox AA, Carroll WE, Sterling RE, Davis HA, Ware AG. Use of the berthelot reaction in the automated analysis of serum urea Nitrogen. Clin Chem. 1966;12(3):151-157.

42. Perakis N, Wolff CM. Kinetic approach for the enzymic determination of creatinine. Clin Chem. 1984;30(11):1792-1796.

43. Bhuta UM, Ulstein $H$. Evaluation of the Beckman Coulter AcT 5 diff AL hematology analyzer in a hospital setting. Lab Hematol. 2003;9(3):167-174.

44. Cong W, Tao R, Tian J, Zhao J, Liu Q, Ye F. EGb761, an extract of Ginkgo biloba leaves, reduces insulin resistance in a high-fat-fed mouse model. Acta Pharm Sin B. 2011;1(1):1420.

45. Kudolo GB. The effect of 3-month ingestion of Ginkgo biloba extract (EGb 761) on pancreatic $\beta$-cell function in response to glucose loading in individuals with non-insulin-dependent diabetes mellitus. J Clin Pharmacol. 2001;41(6):600-611.

46. Buettner R, Schölmerich J, Bollheimer LC. High-fat diets: Modeling the metabolic disorders of human obesity in rodents. Obesity. 2007;15(4):798-808.

47. Jiang $\mathrm{T}$, Wang Z, Proctor G, Moskowitz S, Liebman S, Rogers $T$, et al. Diet-induced obesity in C57BL/6J mice causes increased renal lipid accumulation and glomerulosclerosis via a sterol regulatory element-binding protein1c-dependent pathway. J Biol Chem. 2005;280(37):32317-32325.
48. Hyde R. Europe battles with obesity. Lancet. 2008;371(9631):2160-2161.

49. O’Neill S, O’Driscoll L. Metabolic syndrome: A closer look at the growing epidemic and its associated pathologies. Obes Rev. 2015;16(1):1-12.

50. Atefehalsadat S, Mohammed Abdullah A, Mustafa Ahmed A, Sanaz K, Zahurin M. Medicinal plants and their inhibitory activities against pancreatic lipase: a review. Evidencebased Complement Altern Med. 2015;2015(1):1-13.

51. Seifarth C, Schehler B, Schneider HJ. Effectiveness of metformin on weight loss in non-diabetic individuals with obesity. Exp Clin Endocrinol Diabetes. 2013;121(1):27-31.

52. Banin RM, Hirata BKS, Andrade IS, Zemdegs JCS, Clemente APG, Dornellas APS. et al. Beneficial effects of Ginkgo biloba extract on insulin signaling cascade, dyslipidemia, and body adiposity of diet-induced obese rats. Brazilian J Med Biol Res. 2014;47(9):780-788.

53. Park HK, Ahima RS. Leptin signaling. F1000Prime Rep. 2014;6 (9):73.

54. Kaur Khokhar K, Sidhu S, Kaur G. Relationship between serum leptin and type 2 diabetes mellitus and their association with obesity and menopausal status. Sch Res Libr Arch Appl Sci Res. 2013;5(5):38-44.

55. Gruzdeva O, Borodkina D, Uchasova E, Dyleva Y, Barbarash O. Leptin resistance: Underlying mechanisms and diagnosis. Diabetes, Metab Syndr Obes Targets Ther. 2019;12(1):191-198.

56. Zhao Q, Gao C, Cui Z. Ginkgolide A reduces inflammatory response in high-glucosestimulated human umbilical vein endothelial cells through STAT3-mediated pathway. Int Immunopharmacol. 2015;25(2):242-248.

57. Rehman K, Akash MSH. Mechanisms of inflammatory responses and development of insulin resistance: How are they interlinked? J Biomed Sci. 2016;23(1):87-104.

58. Zhou YH, Yu JP, Liu YF, Teng XJ, Ming M, Lv P, et al. Effects of Ginkgo biloba extract on inflammatory mediators (SOD, MDA, TNF- $\alpha$, NF- $\kappa$ Bp65, IL-6) in TNBS-induced colitis in rats. Mediators Inflamm. 2006;2006(5):1-9.

59. Mir MA, Albaradie RS. Immunomodulation of inflammatory markers in activated macrophages by leaf extracts of Gingko biloba. Adv Neuroimmune Biol. 2015;6(1):9-17.

60. Hussain T, Tan B, Yin Y, Blachier F, Tossou MCB, Rahu N. Oxidative Stress and Inflammation: What Polyphenols Can Do for Us? Oxid Med Cell Longev. 2016;2016(1):1-9.

61. Elmarakby AA, Sullivan JC. Relationship between oxidative stress and inflammatory cytokines in diabetic Nephropathy. Cardiovasc Ther. 2012;30(1):49-59. 
62. Popa-Wagner A, Mitran S, Sivanesan S, Chang E, Buga A-M. ROS and Brain Diseases: The Good, the Bad, and the Ugly. Oxid Med Cell Longev. 2013;2013(1):1-14.

63. Ghezzi P. Role of glutathione in immunity and inflammation in the lung. Int J Gen Med. 2011;4 (1):105-113

64. Sandoval R, Lazcano P, Ferrari F, Pinto-Pardo $\mathrm{N}$, González-Billault C, Utreras E. TNF- $\alpha$ increases production of reactive oxygen species through Cdk5 activation in nociceptive neurons. Front Physiol. 2018;9(2):1-13.

65. Xie H, Wang JR, Yau LF, Liu Y, Liu L, Han $\mathrm{QB}$, et al. Catechins and procyanidins of ginkgo biloba show potent activities towards the inhibition of $\beta$-amyloid peptide aggregation and destabilization of preformed fibrils. Molecules. 2014;19(4):5119-5134.

Baghdad Iraqi Journal Pharmaceutical Sciences by bijps is licensed under a Creative Commons Attribution

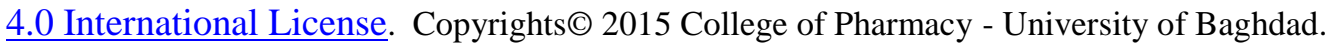

